\title{
Coaching and Mentoring. Concepts and Practices in Development of Competencies: A Theoretical Perspective
}

\author{
Khalid Said Al Hilali ${ }^{1}$, Badar Mohammed Al Mughairi², \\ Mooi Wah Kian ${ }^{3}$, Asif Mahbub Karim ${ }^{4}$ \\ ${ }^{1,2}$ PhD Researcher, Binary University, Malaysia \\ ${ }^{3}$ Adjunct Professor, Binary University, Malaysia \\ ${ }^{4}$ Dean, Binary Graduate School, Binary University, Malaysia, \\ ${ }^{4}$ E-mail: drasifmkarim@gmail.com (Corresponding author)
}

\begin{abstract}
One of the rapid growths in coaching and mentoring has been evident in recent years, reflecting the increased attention paid to the different development elements. It is clear that this growth included almost all sectors, primarily educational, medical, and industrial, and many others. However, the widespread popularity of this attention has been attributed mainly to the sequential reactions about the effectiveness of development elements, particularly professional coaching and mentoring, due to significant gaps in research, studies, and statistics. Coaching and mentoring are part of educational or professional training to develop employees in the professions. Coaching and mentoring play an essential role in the development of competencies and maintain them in their specialization and the sustainability of making the most of them in the service of organizations operating in any sector. There is a mix between the different concepts of career development among the various institutions operating in the industry, in line with plans that may not serve the axis of career development for employees. Also, this study defined multiple similarities and differences in the main issues involved in coaching and mentoring most of these related either to the self-development, professional growth, and career development of the employee. When determining the methods to be used in coaching and mentoring, consideration must be taken to ensure that each member of this relationship understands their limits and the boundaries of the relationship itself. It may be necessary to point out that there is a way out from this relationship as it is to encourage its development in the first place. Supervisory methods vary and depend on the people involved, the location of the meeting, and the terms of the relationship. Not only Coaches/mentors should play their part, but also coachee and mentee as well, and all this should be documented and put in a specific institutional meaning. Therefore, this paper will review the literature of both coaching and mentoring' concepts, and its practices, as well as the definition of coach, mentor, coachee, and mentee, and the relationships between them.
\end{abstract}

Key words Coaching and Mentoring, Effectiveness of Development, Career Development

\begin{tabular}{|c|c|c|}
\hline Received: & 06 Feb 2020 & (C) The Authors 2020 \\
\hline Revised: & 16 Feb 2020 & Published by Human Resource Management Academic Research Society (www.hrmars.com) \\
\hline $\begin{array}{l}\text { Accepted: } \\
\text { led Online: }\end{array}$ & $\begin{array}{l}25 \text { Feb } 2020 \\
10 \text { Mar } 2020\end{array}$ & $\begin{array}{l}\text { This article is published under the Creative Commons Attribution (CC BY } 4.0 \text { ) license. Anyone may } \\
\text { reproduce, distribute, translate and create derivative works of this article (for both commercial and } \\
\text { non-commercial purposes), subject to full attribution to the original publication and authors. The full } \\
\text { terms of this license may be seen at: http://creativecommons.org/licences/by/4.0/legalcode }\end{array}$ \\
\hline
\end{tabular}

\section{Introduction}

This paper discusses the concepts and practices of coaching and mentoring. The Coaching and mentoring concepts are rapidly building their research bases in different sectors, mainly in Education (Orenstein, 2007, Vogt and Rogalla, 2009), adult education' (Brock, 2010), behavioral sciences, nursing (Haider, 2007), psychology, and sports sectors (Coaching, 2003). Many people today may not realize that 
when we talk about Coaching and mentoring, we are talking about two different business terms, The presence of these terms in the constant connection did not come in vain, but-but instead the result of a thorough scientific effort and broad practical experience.

Researchers in the coaching and mentoring Field claim that it is one of an old idea and started rulers and leaders appointed so-called Coach or mentor to provide advice and to guide, as well as the training of their children to reach the luxury image of the sons of the upper classes and wealthy people. The history did not veil the concept of Coaching and mentoring, and even openly talking about a lot of valuable reality stories and novels as a story of the adviser of Telemachus, who was the son of Odysseus, and the influence of Merlin in King Arthur's life. Moreover, the Islamic leaders and princes who used the politer or the courteous (Al Moadeep or Al Moalem) who were appointed as teachers and advisors to teach the cultured, the manners to the sons and daughters. Over time, the concept of Coaching and mentoring become more exciting and widespread and comprehensive as no longer limited to education, health, and many other sectors such as sports psychology, and administration (Joo et al., 2012). Coaching and mentoring are essential parts of the professional training and development of employees at the workplace, which targets explicitly significant improvements and high competence of employees in the workplace and generally focuses on specific goals and skills; but may also have some effects on the individual's characteristics such as confidence and social communication.

Based on the Chartered Institute of Personnel and Development (CIPD) in 2013 definition, "Coaching and mentoring are development techniques based on the use of one-to-one discussions to enhance an individual's skills, knowledge, or work performance." However, some companies refer to the activities of coaching and mentoring in general terms such as Business Coaching and mentoring Executive coaching and mentoring, skills coaching and mentoring, personal (life) coaching and mentoring, and performance coaching and mentoring.

Organizational development requires the provision of crucial professional staff, and the necessary support for them with support is one of the reasons that inspire companies to use business coaching and mentoring. This trend directed at senior managers and corporate managers, but now its results and need for all as a professional or personal development tool for professional development. Business Coaching and mentoring have been closely linked to organizational change initiatives to help employees accept changes and adapt them in a manner consistent with their values, goals, and personal aspirations. Individualized coaching and mentoring can enhance morale, motivation, and productivity, and individuals feel valued and connected with all small and significant organizational changes.

\section{Literature review}

\subsection{Coaching}

The CIPD stated that "Coaching targets high performance and improvement at work and usually focuses on specific skills and goals, although it may also have an impact on an Individual's attributes such as social interaction or confidence. The process typically lasts for a relatively short defined period, or forms the basis of an on-going management style". Eric Parsloe, The respected author and Director of the OCM in his Book: The Manager as Coach and Mentor (1999) page 8; defined Coaching as: "a process that enables learning and development to occur and thus performance to improve.

To be successful, a Coach requires knowledge and understanding of the process as well as the variety of styles, skills, and techniques that are appropriate to the context in which the coaching takes place". In 2009, Marx stated that coaching had gained a reputation as an effective means of developing one's capabilities and improving one's performance. Then, from these standard definitions, we can define coaching as a professional partnership between the coach and coachee based on enhancing the Ideas and encourage employees to increase their professional competency. Coaching is an "internal organized practice" that focuses mainly on improving the employee's performance and eventually benefiting the organization. The primary relationship in the coaching is to encourage and facilitate the Coachee by developing the skills required for the position, and in the end, the performance evaluated, and the feedback is given (Cummings and Worley 2004).

The organizations arrange the Coaching programs according to different requirements such as the organization requirements and the employee's development requirements. These programs should be 
aligned with improved performance to reach the competencies required by the individual. They should also take into account professional, physical, educational, and psychological capabilities required of the employee who needs performance and the responses needed to improve these performances and competencies. Coaching can be considered to serve a single purpose in the interests of the Organization, but in practice, it also provides the necessary support to the employee as individuals to be able to face any current or even future challenges as well.

Because it is the duty of the coach in the first place first to analyze the current situation of the employee, which is expressed by self-reliance, and finding weaknesses and strength to develop later in order to raise the current level, and make him confident enough to meet the challenges of the future (Chiaramonte and Higgins, 1993). The definitions of coaching varied according to the need or objective for which this definition was developed. Therefore, several definitions emerged, most of which were related to the method, outcome, or purpose of the description. More than that is the going of many studies to either reconcile or differentiate between the coaching, mentoring, and other administrative names used in the development and training of employees.

That is what Grant points out (2001) when he said that the definitions vary in clarity and succinctness. The use of the term "Coaching" dates back to the latter part of 1880, and this term was often associated with the sports sector through its various forms that it is why, to this day, it is related to sports when we talk about coaching, since this profession is often developed and very used in sport filed (Evered and Selman, 1989). That attempted to clarify the idea of coaching is that a straightforward explanation of this general term is the fact that professional coaching is a real scientific method that focuses on directing and training either an individual or a group of people with a single aim to achieve specific goals and objectives. By the end of the 18th century and the beginning of the 19th century, the appearance of philosophy as a separate branch from the mother social sciences led to exclusive and unique studies aimed to explore and investigate the complexities of human society and the individual as such. Psychology emerged in its original form during this time where there was an unclear explanation of mental functions and perceptions. The nineteenth-century $A D$ is the beginning of the science of modern administration where it is likely that much in the middle of this century has been developed a lot of theories and ecology, including training, motivation, coaching, mentoring, and other sciences that represent the so-called modern management science, which appeared an official appearance during the industrial revolution.

The period from 1900 to 1930 is characterized by technological progress, the evolution of the scientific perspective, the flourishing of industrialization, and the discovery of the theory of relativity in physics. That is what Goldman wanted when he said: "It is transformed from the Mechanic model into the organic model of the world." This period can be considered the period of establishing the root bases of training for many considerations in line with the industrial revolution. Since 1900, there has been a clear difference in how managers use scientific theories in managerial performance to respond to an industrial revolution that indeed requires specialization in work, leadership unit, proper hierarchy, and coordination of activities. Then over the next 20 years, the emergence of the scientific and classical administration began to emerge, and the movement of human relations also began. The well-known Hawthorne studies were developed in the 1920s, and business theories and practices began to adopt approaches and psychological models of business administration. From 1930 to 1950, the progress of technology continued during this period, and current production targets began to invade our lives.

The military model of control and leadership began to dominate almost every aspect of life, such as management, education, consulting, and development. The emergence and establishment of behaviors during this period was also a reaction to Freud's theories. In the 1950s, Maslow and Rogers reached a new humanistic approach to psychology known as the Third Power of the Sector (Hall, 1999), where the personal and virtual aspects of the human experience were given higher priority and attention. With the beginning of the 1960th, movements in support of human and civil rights began to appear, mainly by advice employers that employees needed to be treated well, land that many social and public aspects were taken into account. We can say that at this point, the references to training from human resources magazines have developed and are beginning to appear more in the areas of practice and management. In the period from 1960 to 1979, several 15 of the 23 written articles on the subject of coaching were available in training journals. 
Coaching began to add primary significance, and there were four administrative books published in training. The main topics that were acquired were the essence of these books on how managers use coaching to improve employee's performance and competency. The period between the seventies and eighties was necessary and critical in the history of Coaching and mentoring. In the United States of America, during this period, the potential of coaching and mentoring in the business sector began to emerge. The experience here concluded that training is vital to support Employees so that they can meet their performance requirements. During this period, the training and mentoring capabilities of the business sector have begun to emerge. The experience there has proven the importance of these two concepts to support employees so that they can meet their performance requirements and can also help in sustaining and successful business. Dennis C. Kinlaw $(1990,1997,1996,1999,2000,2013)$ is one of the names that called for the importance of coaching, and it must include two main features: individual conversations and a focus on performance or performance issues.

While in Britain, coaching has new meaning because it correctly pointed out that coaching is the process by which it can have direct discussions among the staff themselves to find solutions to the problems they face to complete the tasks assigned to them. These two examples confirm the 1980s growth in Kuching and its full dominance in business literature. This been reflected in the acceptance of the discipline journals of the terms of coaching and mentoring as a new and useful term and the publication of many articles on this concept. The period between the seventies and eighties was also the time in which the roots of the necessary Coaching and mentoring are traceable to the essential resources which are related to the development of leadership skills and management practice of knowledge and understanding skills. The significant growth that accompanied the 1990s was also accompanied by substantial progress in the importance of coaching in the business explosion and development through the development of employees, coaching, and mentoring.

Through the writings and references specialized in the business sector and the development of human resources, we are surprised by the massive amount in which the terms of coaching and mentoring were mentioned. We can say that these increases and developments in the training industry have been phenomenal and reached maturity during this period in terms of the experience of training and coaching accumulated, increasing the number of specialists and experts in the field of coaching and mentoring to enhance the development of management and human resources. Many books were published that dealt directly with coaching at this period, and the articles of the journals began to focus on the topics of coaching and mentoring, which also began to branch to other administrative fields. Some sources note that 39 books on coaching were published in the early part of the first decade of the 21st century. It is stated in some sources that (Whitmore, 2010) was in this period, specifically in 1992, the author of his book known as "Coaching for performance," which circulated the GROW model. Despite the overload of declares claimed by this remarkable model, many studies have referred to more than one name as the actual creator of this model, including Graham Alexander and Alan Fire.

However, the GROW model is the most common among all modules (Other similar models include collaborative helping maps in family therapy, Gabriele Gottingen's WOOP model, and others). It is a simplified way in which goals are defined and problems solved. It was agreed that this model was developed in the UK and was widely used in training for employees in various sectors and institutions in the late 1980s and 1990s. In recent years, the concept of coaching has been able to adapt and integrate with many models through which the root specialties of coaching can be employed in various business sectors and theories in the psychological section, especially for this purpose. Similarly, there were also effects on coaching from different disciplines such as anthropology, sociology, and linguistics, and the relationship between coach and client became the subject of analysis and study. Coaching in business becomes essential in the corporate and business world, and Organizations today realize that they cannot move in the right direction without including coaching in their development. It is also aware of the significant impact that the integration of coaching in the strategies and plans, which will enhance the productivity and effectiveness of the company and employees alike. Grant (2001) notes that the differences in definitions obtained for professional coaching through their degree of clarity and concision were the result of the multiplicity of these definitions. Joe's description (2005), of coaching, came as "a process of a one-on-one relationship between a professional coach and an executive (coachee) for the purpose of enhancing the 
coachee's behavioral change through self-awareness and learning, and thus ultimately for the success of [the] employee and [the] organization. (Hamlin et al., 2008) Reviewed the experimental literature associated with the training using the empirical position and finally collected some definitions of juicing, drawn initially from two studies by Grant (2001) and Joe (2005), and other definitions from their literary research.

The difference in these definitions is related to the study of the complexity and comprehensiveness of the process itself. Hamlin et al. (2008) list thirty-seven descriptions of coaching, but in my view, only eight of these definitions capture a wide range of training activities such as empowerment, performance improvement, transformation, self-learning, and personal growth that are relevant to this study. These definitions were organized according to the date and the remarkable observation of these definitions in the world. Table1 is an example of the different training definitions chosen from Hamlin et al. (2008), and other authors and study. The table shows the training history of definitions in each period, and what distinguishes each definition for the period in which it was found and the reflection of this definition on the definition and understanding and applications of professional coaching in the present time and use.

Table 1. Different training definition

\begin{tabular}{|c|c|c|}
\hline Definitions & Authors & Remarks \\
\hline $\begin{array}{l}\text { Coach-Meaning "instructor/trainer" is c. } 1830 \\
\text { Oxford University slang for a tutor who "carries" a } \\
\text { student through an exam; the strong sense is } \\
\text { 1861. The verb is from the } 1610 \text { s, "to convey in a } \\
\text { coach;" meaning "to prepare (someone) for an } \\
\text { exam" is from } 1849\end{array}$ & $\begin{array}{l}\text { Oxford University } \\
1849\end{array}$ & $\begin{array}{l}\text { The first appeal of the word Coach in the } \\
\text { history }\end{array}$ \\
\hline $\begin{array}{l}\text { Establish basic training disciplines during this } \\
\text { phase } \\
\text { From the 1900s, there was a significant difference } \\
\text { in how managers used scientific theories in } \\
\text { managerial performance in response to the } \\
\text { Industrial Revolution } \\
\text { In 1910, a remarkable scientific and classical } \\
\text { administrative perspective began to emerge } \\
\text { The famous hawthorn studies were developed in } \\
\text { the 1920s, and business theories and practices } \\
\text { began to adopt theories and psychological models } \\
\text { to manage }\end{array}$ & $\begin{array}{l}\text { The 1900s through } \\
\text { 1920s }\end{array}$ & $\begin{array}{l}\text { the period for technological advances } \\
\text { and the scientific perspective was at its } \\
\text { peak at this time } \\
\text { a clear difference in how managers use } \\
\text { scientific theories in managerial } \\
\text { performance to respond to an industrial } \\
\text { revolution that indeed requires } \\
\text { specialization } \\
\text { Initiation of the human movements }\end{array}$ \\
\hline $\begin{array}{l}\text { Coaching refers to the managerial activity of } \\
\text { creating, by communication only, the climate, } \\
\text { environment, and context that empower } \\
\text { individuals and teams to generate results. }\end{array}$ & $\begin{array}{l}\text { Evered and Selman } \\
\text { (1989) }\end{array}$ & $\begin{array}{l}\text { Sports Coaching was introduced to the } \\
\text { management Field By 1950th }\end{array}$ \\
\hline $\begin{array}{l}\text { Coaching is a process that enables learning and } \\
\text { development to occur and performance to } \\
\text { improve. }\end{array}$ & Parsloe (1995) & $\begin{array}{l}\text { *Detailed description of the principles of } \\
\text { training, guidance, necessary skills, and } \\
\text { appropriate training methods. } \\
\text { * How to establish a person's } \\
\text { professional competence through a } \\
\text { series of simple self-evaluations. } \\
\text { * Put learning theories into practice }\end{array}$ \\
\hline $\begin{array}{l}\text { Coaching is, exclusively, a process focusing on } \\
\text { enhanced performance. }\end{array}$ & Burdett (1998) & $\begin{array}{l}\text { Identify the word ( enhance) within the } \\
\text { definition of coaching }\end{array}$ \\
\hline $\begin{array}{l}\text { A coach is a person who facilitates experiential } \\
\text { learning that results in future-oriented abilities } \\
\text { and who is trained and devoted to guiding others } \\
\text { into } \\
\text { increased competence, commitment, and } \\
\text { confidence. }\end{array}$ & Hudson (1999) & $\begin{array}{l}\text { Identify the trainer and assign some of } \\
\text { his duties academically }\end{array}$ \\
\hline
\end{tabular}




\begin{tabular}{|l|c|l|}
\hline \multicolumn{1}{|c|}{ Definitions } & Authors & \multicolumn{1}{c|}{ Remarks } \\
\hline $\begin{array}{l}\text { [Coaching] is a collaborative, individualized } \\
\text { relationship between an executive and a coach, } \\
\text { the aims of which are to bring about sustained } \\
\text { behavioral change and to transform the quality of } \\
\text { the executive's working and personal life. }\end{array}$ & $\begin{array}{c}\text { Zeus and Skiffington } \\
(2000)\end{array}$ & $\begin{array}{l}\text { The relationship, and the sustainability } \\
\text { benefit of the coaching }\end{array}$ \\
\hline $\begin{array}{l}\text { [Coaching] is a robust process that supports } \\
\text { people in releasing their real potential and in } \\
\text { making changes in their lives. }\end{array}$ & Richardson (2004) & The process for real optional and change \\
\hline $\begin{array}{l}\text { Professional coaching is a theoretically grounded, } \\
\text { systematic, goal-directed process designed to } \\
\text { facilitate sustained change and foster the on-going } \\
\text { self-directed learning and personal growth of the } \\
\text { coachee and is aimed at skills development, } \\
\text { performance enhancement, and personal } \\
\text { development. }\end{array}$ & $\begin{array}{c}\text { Grant and Cavanagh } \\
\text { (2004) }\end{array}$ & $\begin{array}{l}\text { Professional coaching and sustainable } \\
\text { change }\end{array}$ \\
\hline $\begin{array}{l}\text { Professional coaching is an ongoing professional } \\
\text { relationship that helps people produce } \\
\text { extraordinary results in their lives, careers, } \\
\text { businesses, or organizations. It deepens learning } \\
\text { to improve performance and enhance the quality } \\
\text { of life. }\end{array}$ & Federation (2007) & $\begin{array}{l}\text { Summarizes } \\
\text { development, and change }\end{array}$ \\
\hline
\end{tabular}

\subsection{Coach}

A coach's primary responsibility is to enhance the capabilities and skills of the employees to achieve their potential in a profession or areas that need improvement. The role of a coach provides a kind of support distinct from any other. The coach will focus exclusively on the situation with the kind of consideration and commitment that you rarely experience elsewhere. The Coach can help the employees change to the extent they wish and helping them go in the direction they want to go. A coach can be used to support the employee at every level in becoming whom they want to be. Coach is also required to develop specific skill sets and goals relevant to the job or type of recreation. The coach has often been related to a teacher (Oermann and Garvin, 2001). Other authors and studies propose that coaching is a form of learning or training (Frost, 1971; Mink et al., 1993). Coaching has also been linked to the sports sector, but in the last few years, coaching has become applicable in every area and industry, such as business and every aspect of life as well.

The coach can also be seen as an energizer, trainer, or adviser (Lyle 1985) and should be valuable as a source of supervision development, preparation, and motivation on how to improve the performance of a coachee (Maher 2001). The coach should help to form the welling of the Coachees and be able to crystallize visions and values. These services can require some skills in change management, locality strengths, and limitations, and outline strategy. Other skills the coach has to have are coordinate resources to achieve goals, optimize performance, satisfaction, and balance in life and stay accountable to a view, analyzing current performance, designing proper learning, and evaluating performance (Antonioni, 2000; Lyle, 1985). Coaches can take several definitions or duties depending on the context in which they operate. In a business context, for example, the coach is a partly advisor and is often interested in helping the coachee identify and achieve his or her career and personal goals, or both at the same time. The coach is also interested in considering what will be in the future more than what was in the past, so we see that he does not seek any old history of the coachee or previous achievements as a quest to know what the coachee wants from the future. The coaches will work to find solutions with the Coachees and not tell directly, in the sense that the coachee will be involved personally in finding these solutions. The coach can provide vision into current problems and suggest a wide range of options.

On the other hand, Smith takes the view that such a coach should help the coachee to think about things, develop the structures upon which to work, monitor progress, and help to keep on track. According to Wough (1997), and Franklin (2000): Instead of allowing the solution directly to the Coachee, the professional coach can use his experience and skills to get the coachee to the stage of finding solutions on 
their own, or at most to help them reach this stage of ability and experience. Beam (2001) identified some of the characteristics to be provided in the excellent coach (in the nursing sector), including professional experience, the ability to evaluate the coachee to explore personality chemistry, find some checkpoints to measure progress and make a mid-course correction. While in the sports sector: Franklin (2000) says that the role of the coach in the sports sector is to make the most of the talents of the players, and in business sector: the corporate coach does the same by helping employees develop and use their skills most effectively and productively. Therefore, the role of both sports coaches and companies is to create an environment where there are a challenge and the potential for personal growth and professional development.

By studying the various characteristics to be provided in the trainer in different sectors, it shows us that the relationship based on trust and transparency is the basis of any successful coaching relationship: Their skills, their enthusiasm to learn, their willingness to become more skilled and productive. The coach must seek the respect of those who work with them by sharing stories from their own experiences or by setting examples. Before proposing any ideas and sharing experiences with employees, the trainer should have a clear understanding of the knowledge of each employee (Bowers, 1972).

\subsection{Coachee}

Most studies and researchers agree that the coachee must set his/her own goals when adopting any coaching relationship. In the business and management sector, coaching is designed to support the Coachees in achieving more success in career, especially in terms of what do in the daily duties and work. The Coachee must be open-minded, constructive, and critical. The coachee should also be able to comply with what agreed upon in any orientation program and must commit to improving behavioral causes and outcomes. A person's ability to assess his or her personality or job performance will help him to know his character more clearly, and it will give him/her a broader idea of his abilities and possibilities.

Researchers have attempted to identify some of the personal benefits Coachees can gain if they can assess themselves: identifying and overcoming obstacles, building self-confidence, building self-reliance, developing and applying a new skill, and learning from mistakes and achievements. On the professional side, the coachee can, in addition to the above, improve the ability to design action plans, and enhance his/her ability to develop new ideas and strategies. The coachee must also be aware of the various circumstances, possibilities, opportunities, and threats that surround him. He/she must be able, to be honest in assessing his skills and accept some sacrifices for their development. The coaching relationship in which the coachee can work may require a lot of meetings and documentation. The coachee must adhere to these meetings in all their forms, whether face-to-face (Direct meetings), telephone conversations, or Email correspondence (Bolch, 2001).

It should be noted that the coachee may be able at the beginning of this relationship to determine the type of meetings preferred, but this does not prevent the use of other methods of meetings. The coachee before accepting any coaching relationship should know the challenges he/she faces in doing his job, and to understand the goals he/she wished to reach through this coaching relationship, as he/she should evaluate the skills he/she currently has to perform his work, or what he/she can offer more of competencies and skills. So this is important to help the coach determine the method of learning preferred by the coachee and also to assess the level of preparation and knowledge he needs to provide coaching. The coachee should show his/her willingness and commitment to the coaching program by interacting with the coach and providing him/her with all the information and data he/she needs to make the coaching relationship a success. Some coaches insist on setting up face-to-face meetings at organized times during the coaching relationship, while others rely more on phone calls or discussing developments through e-mail (Bolch, 2000).

According to Kate Nasser (a people skills coach) 2004: In the business sector, these meetings should be conducted according to the need of the stage of the coaching relationship, while Xavier (2004) proposed that these meetings depend on the level of participation of the person being coached. Therefore, these meetings can be held once a week or once every two weeks or once a month to give the appropriate and sufficient time to the coachee to complete the coaching program with comfort and awareness without 
thinking about preparing meetings and others. These coaching Conversations (Meetings) must be short and brief, lasting five to fifteen minutes in maximum.

Studies and researchers explain this with the results that proved that brief conversations have more impact in any development relation, while more extended conversations tend to open the door for issue skipping and additional unnecessary feedback. The coachee in this coaching relationship should assume his/her responsibilities as in any form of development at work. The coachee must also commit to the hard work, risks, and uncertainties that are part of the real and sustainable impact. In other words, the coachee must endure his/her progress while working on it consistently and with commitment, with confidence in the coach to be there with all the necessary support and experience. Moreover, everyone needs to understand the risk of a person making the change and the subsequent fear of failure that could result. If the coachee is not keen to make this level of commitment, or, as sometimes happens, if the organization is not ready to be supportive, it is up to the instructor to identify this problem and clarify expectations and continue or abandon the project as it needs.

\subsection{Relationship between Coach and Coachee}

The nature of any Coaching relationship established between the coach and the coachee seems to be a key process variable. Many scholars and studies have suggested that the relationship between coach and coachee constitutes an essential condition for the success of any Coaching program (Palmer, 2010). Some of these studies and conclusions indicated that the coach-coachee relationship plays a mediating role between the coaching received and the development of the coachees' self-efficacy. Findings also show four important correlates to the coach-coachee relationship: the coach's self- efficacy about facilitating learning and results, the coachee's motivation to transfer, his or her perception of supervisor support, and the number of coaching sessions received (Baron and Morin, 2009).

Based on that, the coach-coachee relationship can be described as a partnership, one in which both sides work together to reach an agreed-upon objective. Both the coach and the coach are very vital to achieve the success of this relation. The relationship is not one of the equals, however. The setting of the goal is the welling of the coachee with the help of the coach in setting the ground rules, collect the necessary data about the employee, evaluate, analyze and assess the situation, monitor progress of the relation,, and define the right action plan, push or prod accordingly, All of the above stages needs to be done openly and transparently with the full cooperation of the coachee.

The experience and the skill of the coach will lead these processes in the relationship accordingly. In the Manager's Intelligence Report, published in 2000, five essential steps for establishing and building a more effective and more productive coaching relationship were identified: (1) Start building trust between the trainer and the interns through face-to-face meetings. (2) Discuss everything related to the coaching relationship, confidentiality, and the information that will help the coachee. (3) Help the coachee determine what goals he/she will need in this relationship. (4) Communicate for the first meeting with the coachee. (5) Do not hesitate to give feedback and alerts that help to increase confidence and thus raise the level of questions provided by the coachee in this relationship. In the opinion of Bernard 1994 that the involvement of the trainee in this relationship must include the most prominent of these necessary steps, such as setting goals, communication, and make observations and feedbacks. The role of the CoachCoachee relationship highlighted in influencing coaching results and benefits. In 2012 Grant conducted an exploratory pilot study to explore four aspects of the coach-and-coachee relationship to investigate and linked to specific measures for the success of the coaching. These aspects included: (1) support for the coachee's independence. (2) The intern's internal satisfaction with the training relationship. (3) Focus on the objectives of the training relationship. In the grant's study, multiple measures of the relationship between the coach and the coachee were used to directly analyze the corresponding effectiveness of the different aspects of the relationship between the coach and the coachee.

Howard J. Morgan also incorporated some necessary steps to create a robust coach-coachee relationship. Howard J. Morgan also combined some critical steps to create a healthy coach coachee relationship that has relied entirely on creating an environment of understanding and satisfaction between the two sides of the relationship that allows both parties to succeed in the goals of this relationship. Some of these steps are summarized below: (1) Setting the basic rules of this coaching relationship. (2) Significant 
of the commitment of the parties involved in the provision of the training relationship. (3) The coachee' understands the benefits that come to them through this relationship. (4) Determining how data and information will be collected and confidentiality defined in the relationship. (5) The coachee's accumulated knowledge and focus on two-three main issues they believe are crucial to achieving vital changes .(6) Agree on how to communicate and make observations.(7) Agreement between the coach and the coachee on the duration of the coaching relationship, how to evaluate it later, and follow it up after it's over. The various studies also indicate that the coaching relationship that focused on goal setting has helped a lot and more strongly in the success of the coaching relationship. The results emphasize the importance of objectives in the coaching process and highlight significant differences between alliances in the field of coaching.

\subsection{Mentoring}

David Clutterbuck \& David Megginson, in their book: Mentoring Executives and Directors (1999) stated that mentoring is an "off-line help by one person to another in making significant transitions in knowledge, work or thinking." CIPD mentioned that mentoring is basically to describe a relationship in which a more experienced colleague uses his or her more excellent knowledge and understanding of the work or workplace to support the development of a more junior or inexperienced member of staff. In 2004: Luecky mentioned that mentoring has proved to facilitate the transfer of tacit knowledge and enact professional standards. Suzanne Faure defined Mentoring as a "supportive learning relationship between a caring individual who shares his/her knowledge, experience, and wisdom with another individual who is ready, willing, and able to benefit from this exchange to enrich their professional journey".

Therefore, mentoring can be defined as professional learning related to transfer knowledge and professionalism between an experienced, knowledgeable employee and less experienced, knowledgeable employee. Many of the definitions in professional mentoring are due to the kind of professional mentoring applied at the academic level, including the process of helping the individual to make the right professional decision in the academic choice, and thus the profession appropriate to his preparations, abilities, tendencies, preparation, and enrollment. Both Weaver and Chelladurai (1999) defined Mentoring as a process in which an experienced professional plays the role of a mentor who provides support, assistance, and guidance to a less experienced person as a mentee, and steers career progress and bath to him. Pertin in 2011 defined mentoring as the professional relationships in which a qualified individual (Mentor) assists another less experienced person called mentee in developing challenging knowledge and skills which can promote personal and professional growth.

According to Marquardt and Loan (2006), mentoring can be defined as the "Off-line help by one person to another in making significant transitions in knowledge, work, or thinking." Marquardt and Loan tried to explain the relationship as a kind of support provided by one person with the necessary expertise and knowledge to someone else who lacked it in through an individual link created through regular communications over a specified period. However, according to Megginson and Clutterbuck (2005), mentoring connections to recognition and development of chances for an individual which can be longterm procedures in which the objectives might change but are always determined by the mentees. Mentoring definitions have been examined, debated by scholars (Allen and Eby, 2010). Mentoring can be a life-altering relationship primarily when directed toward professional development (Hezlett and Gibson, 2005). Mentoring is often relevant 'when learners are making transitions at critical points in their lives, and mentoring may be associated with the selection, career and personal development, career and private support, and change.

Similarly, Shula and Blanchard (2001) mentioned that mentoring involves supporting people in identifying and defining the needs of their development and setting their personal goals and objectives. Encouraging self-governing learners such as: allowing them to talk and raise their complexities, and challenging; help them to reproduce their thoughts, feelings, behaviors, and beliefs, and to observe difficulties from various perspectives; encouraging and guiding them in independent solution and analysis of their opportunities and problems, supporting the settlement of issues by embracing an integrated approach, and enabling them to become effectual in decision making. Mentoring is mainly select capabilities possessed by the employee as a whole, working on sponsorship, and directs the employee to 
the proper methods and tools to achieve the Advantage of them. Therefore, mentoring is a long-term collaboration between the Mentor and mentee (The employee) relationship.

\subsection{Mentor}

One of the first remarks of the term: "mentor" was found in Homer's The Odyssey. A wise man named Mentor was given the task of educating Odysseus' son, Telemachus. Odysseus wanted to entrust the care of his kingdom and his son to Mentor, a wise and trusted mentor (Irby, 2016). The MerriamWebster dictionary defines a mentor as a guide. A mentor is an older individual with more experience who can help advise another employee's development. The mentor's role is to guide, to give advice, and to support the mentee. A mentor can help an employee (mentee) improve his or her abilities and skills by providing guidance and advise through assessment, and observation based on experience and skills gained through years. The American Psychological Association (APA) defined two main functions for the mentors: work-related guidance and development and serving as role models and supports. Therefore, Mentors can provide professional expertise and advice to other individuals called mentees.

There are many roles and responsivities of the mentor in any organization. One of the most traditional roles of a mentor is to help the new employee quickly understand the organization's culture. But the primary purpose of using a mentor is to help the continuing employee develop in their current position and become fit for new jobs and career opportunities. Mentors are also can help in assisting an employee, further to a specific task or area of responsibility, to quickly learn what they need to know to succeed in their job and role. A mentor can also serve as a sounding board as the new employee absorbed into the organization. As we can see from the above definitions and tasks of the mentors developed by researchers and centers interested in development and training, there are many views and descriptions of the role of the mentor, but all include actions such as support, guidance, facilitation, and empowerment.

Hence we can conclude that the most important role of the mentor is to provide guidance, advice and counseling (Parsloe, 1999).

In conclusion, most authors and studies highlight that the most significant role of the mentor is to provide guidance and advice. These roles are substantial in terms of development, training, and mentoring. These skills can help this mentee to review and identify strengths, set goals, and study opportunities. Later these roles are reflected in the mentee as follows: skills development, planning, and implementation of their professional development. Help them set high but achievable goals, make realistic plans, monitor progress, provide feedback, and provide a role model (Evans, 2005).

Mentors must have many qualities because mentoring as a training relationship requires specific characteristics that must be available in the mentor, including good intelligence, integrity, ability, professional attitude, and standards. Such qualities will help the Mentor to meet the expectations of the mentee (Karam 1995).

The mentor should also have other characteristics such as strong personality, flexibility, enthusiasm, desire to share knowledge, negotiation skills, ability to give and receive various responses, evaluation, reporting, and goal setting (Fisher, 1994).

We note from the above characteristics that it must be available in the mentor that they mainly concerned with competence and experience but also depends on the right balance between personal qualities and knowledge of the organization in which the mentoring relationship occurs.

Mentoring is an excellent commitment to time, patience, and listening and communication (Wilson, 1990). It is, therefore, the duty of an excellent mentor to always encourage the mentee based on what they feel comfortable in participating. Understanding what may be partly self-evident for what the learner is trying to achieve Share your experiences, successes, and failures will lead to the breakdown of the walls and encourage the trainee to reciprocate. Moving to professional and straightforward activities together, such as scientific talk, can help build a more confident relationship.

\subsection{Mentee}

When thinking about the mentoring relationship, the focus is always towards the mentor and neglect the role of the mentee in this relationship, although it is the most essential element in this relationship since the relationship was initially established for him/her or more specifically for the development of 
professional or personal and provide him with a resource to help achieve his professional aspirations (Danzger, 2001). Researchers have identified several factors to attract mentee to such mentoring relationships, including but not limited to: providing a range of ways to help the mentor to reach a profitable end to both parties, focus on the clarity and transparency of the daily reality of the work, communicate with the mentor or direct manager about the areas that the counselor needs For the success of a mentoring relationship.

To be included in a mentoring relationship is an opportunity for both participants (Mentor and mentee), and as a result, it is important to be thoughtful.

Some basic bases of what makes the ideal mentee are: (1). Enthusiasm to learn, and willing to test new challenges (Robinson, 2001). (2) Ability and willingness to work as a team player. (3) Patience, openminded to feedback and new ideas, viewing it as an opportunity to improve his/herself (Saul, 2004). (4). be a risk-taker. (5) Have a positive attitude. (6) appreciative of the help and the trust given by the mentor, and (7) Ability to manage the relationship by establishing the first contact and by continuing the relationship (Heinz, 2003).

However, Robbins (1991) adds that to enhance the effectiveness of the mentoring relationship, both parties should be on-time. The mentee should accept the mentor's advice, be honest, inform the mentor of his or her relevant training and employment experience, ask clarifying questions, and then listen carefully.

In conclusion, the mentee should have a sincere interest in developing a personal and professional relationship that supports development towards carrier development or professionalism increase. The mentee should ask for mentoring and invite the first communication with the mentor to set the goals and objectives of this mentoring relationship. These goals and objectives must be well prepared and relevant to career development. The preparation must be through asking specific advising and guidance. The mentor will lead this relationship, but the mentee must use active listing skills, take notes when needed, and ask the right questions with a purpose.

The mentee must take the initiative to ask for feedback. This feedback is significant for professional growth and a clearer career path. The mentee should accept the Honest and even aggressive feedback as these will allows you to improve and help to move towards fulfilling your potential. One of the successful mentoring relationships occurred if the mentee is open-minded to new ideas and suggestions, and asks for specific details about any issue faced in this relationship. The mentee always has to consider all advice or recommendations or commitments receive, appreciate for every form of assistance, and respect your mentor's time. One of the most positive attitudes of the mentee has to have during this relationship is to be careful not to interrupt and to respect the format, the opportunities, and the limitations of the relationship and always act respectfully towards the mentor. The mentee finally is responsible for following up with the mentor after the end of the mentoring relationship to keep in touch, share progress, and feedback the mentor in order to show more appreciation.

\subsection{Relationship between Mentor and Mentee}

Mentoring is one of the supports of the career development process in any institution and is therefore treated as a catalyst for career success; hence the mentoring relationship is significant in the progress of the career ladder, employee productivity, and professional competence. It is also important to note the understanding of the impact of mentoring on the mentor and mentee sides, and the variables contained in this relationship contribute to the success of the extension relationship, or the effects of mentoring on the productivity of the individual, job satisfaction, professional improvement, and personal development (Straus, 2009). The keys to establishing a successful mentoring relationship include creating a relationship of trust, clearly defining roles and responsibilities, establishing short- and long-term goals, using open and supportive communication, and collaboratively solving problems.

For any mentoring relationship related to succeeding, certain factors must be available to help strengthen the association, its continuity, and eventual success. Initially, this relationship will need to build mutual trust between the mentor and the mentee to add a spirit of cooperation and the ability to exchange opinions, solve problems, and study different aspects. In research specializing in coaching and mentoring, Kutilek \& Earnest state that a well-established environment for trust sharing is essential to better identify the mentor and mentor of each other. 
Determining the roles and responsibilities of you as one of the parties to this guiding relationship is also important because it has a significant role in explaining the course of the relationship and the part of each party in terms of receiving or giving notes, and the questions to be asked in this mentoring relationship, which must take into account different aspects and include multiple possibilities. These questions can be about the role of both the mentor and mentee, the most appropriate and effective types of mentoring for the mentee, the appropriate times for meetings, and other questions directly related to the progress of the pilot process. Short-term and long-term goals must also be set to achieve them during these relationship goals (Podsen \& Denmark, 2000).

The mentee's objectives and the experience of the mentor are often the most important and the most valuable in setting such goals. A mentoring relationship must be characterized by some qualities and skills that must be available on both sides. These characteristics may mostly converge with the properties of the router. Some of these characteristics of the mentor: active listening skills, the ability to provide constructive comments, and the ability to open a door for open and supportive communication of this process. As for the mentee, must have the desire to continue this relationship, accept criticism, take notes and work to review it and accomplish what he can achieve from it, the ability to develop the appropriate plan to solve the outstanding problems and achieve the goals. A positive mentor-mentee relationship highly recommended for a mentee's development, especially in professionalism growth, and in having a clearer career path in the organization. Positive relationships required a healthy trust environment, time commitment, respect from/sides, information sharing, right communications channels, well-defined objective, and proper plans to solve the different issues through this relationship.

\section{Conclusions}

Coaching and mentoring involves more than just introducing a new employee to be more productive and skilled within his position in the organization. Coaching and mentoring are two separate strategies for continuous development, parallel staff needs, and daily routine duties. Coaching and mentoring require much assistance to provide appropriate professionalism and the environment for development, training, capacity, and self-experience related to the establishment of a structure within the organization.

Coaching and mentoring has proven to be critical methods of development and learning used to bring about change, develop efficiency, raise awareness, and change attitudes and behaviors in organizations. Several critical areas of Coaching and mentoring have been investigated.

It is wise, of course, to check the Coaching and mentoring that has already been internally and what is available externally before seeking for any coaching or mentoring relationship. The accurate definition of the coach/Coachee, and Mentor/mentee, and how to build a relationship between them is significant in the right guiding to both associations. It turns out that there are many similarities and differences in the main issues involved in coaching and mentoring, which discussed in this paper. We can summarize the role of the Coaches/mentors in helping Coachees/mentees achieve their goals by working as a consultant, facilitator, and Advisor. This can include support, counseling, evaluation, feedback, and motivation. The coach/mentor must meet conditions such as experience and skills to communicate help in setting goals, analyzing positions, making the necessary plans, and professional skills related to the candidate. All parties in this relationship should trust the other party and act honestly and responsibly by providing the required information and appropriate skills for the success of the relationship. Time is one of the most critical factors for the success of this relationship and commitment to time, agreements and plans is another important factor for success in this relationship.

This paper Contributed to the growing body of knowledge by enrich the understating of interrelationships between external factors, internal capabilities and practices related to the development of coaching, mentoring practices and employee competency. Practically, the results of this paper can also help owners/managers understand what defines a well-developed coaching and mentoring initiative and what other firms are doing in regards to coaching and mentoring practices. Different organizations in different sectors are encouraged to integrate coaching and mentoring policy into their firm's policy as this aspect is highly beneficial to firms who consider the prospects of sustainability. 


\section{Acknowledgement}

The authors would acknowledge the guidance of Global Academics Research Academy (GARA) for journal selection. Moreover, we are grateful to Onism Consultancy for editing and proofreading services.

\section{References}

1. Allen, T. D., and Eby, L. T. eds., (2011). The Blackwell handbook of mentoring: A multiple perspectives approach. John Wiley \& Sons.

2. Antonioni, D. (2000). Leading, Managing and Coaching. Industrial Management, 42(5), 27- 34.

3. Baron, L., and Morin, L., (2009). The coach-coachee relationship in executive coaching: A field study. Human Resource Development Quarterly, 20(1), 85-106.

4. Beam, L. (2001). Would You Like Your Own Coach?. Nursing Homes Long Term Care Management, 50(3), pp.58-60.

5. Bolch, M. (2001). Proactive Coaching. Training, 38(5), 58-63.

6. Bowers, C., Fie, J. U., Kjeldsen, K., and Schmid, A. B. (1972). Judging and Coaching Women's Gym.nastics. Palo Alto.

7. Brock, T. (2010). Young adults and higher education: Barriers and breakthroughs to success. The future of children, 109-132.

8. Clutterbuck, D., and Megginson, D. (1999). Mentoring executives and directors. Routledge.

9. Danziger, K. (2001). Mentors can help further your career. Internet Week, 848(12), pp.49-51.

10. Evans, A. (2005). How mentoring can raise achievement. In Mentoring and Higher Education: The First Aimhigher National Mentoring Scheme Conference (p. 15).

11. Franklin, D. (2000). Coaching For Success. Credit Union Management, 24(12), 50-54.

12. Frost, R. B. (1971). Psychological Concepts Applied to Physical Education and Coaching. Massachusetts: Addison-Wesley Publishing Company.

13. Grant, A. M. (2014). Autonomy support, relationship satisfaction and goal focus in the coachcoachee relationship: which best predicts coaching success?. Coaching: An International Journal of Theory, Research and Practice, 7(1), 18-38.

14. Heinz, H. J. (2003). Mentor Program Guidelines. Available at: http://www.mism.cmu.edu/ mentorsite/programguidelines.asp (Accessed, 2019).

15. Hezlett, S. A., and Gibson, S. K. (2005). Mentoring and human resource development: Where we are and where we need to go. Advances in Developing Human Resources, 7(4), pp.446-469.

16. Irby, B. J., and Boswell, J. (2016). Historical Print Context of the Term, "Mentoring".

17. Kinlaw, D. C. (1999). Coaching for commitment: Interpersonal strategies for obtaining superior performance from individuals and teams. Jossey-Bass/Pfeiffer.

18. Kram, K. E. (1985). Improving the mentoring process. Training \& Development Journal.

19. Kutilek, L. M., and Earnest, G. W. (2001). Supporting professional growth through mentoring and coaching. Journal of Extension, 39(4), 3-13.

20. Luecke, R. (2004). Coaching and mentoring: How to develop top talent and achieve stronger performance. Harvard Business Press.

21. Maher, S. (2001). The Case for a Coach. Association Management, 53(4), 78-84.

22. Marquardt, M. J., and Loan, P. (2006). The manager as mentor. Greenwood Publishing Group.

23. Megginson, D., and Clutterbuck, D. (2006). Creating a coaching culture. Industrial and commercial training, 38(5), 232-237.

24. Mink, O. G., Owen, K. Q., and Mink, B. P. (1993). Developing High-Performance People: The Art of Coaching. Reading, MA: Addison Wesley.

25. Nasser, K. (2004). Coaching. Available at: http://www.katenasser.com/coaching.html (Accessed 2019).

26. Oermann, M. H., and Garvin, M. F. (2001). When coaching new grads... Nursing management, 32(1), 26-27.

27. Orenstein, R. L. (2007). Multidimensional executive coaching. Springer Publishing Company. 
28. Palmer, S., and McDowall, A. eds. (2010). The coaching relationship: Putting people first. Routledge.

29. Parsloe, E. (1992). Coaching, Mentoring and Assessing- A Practical Guide to Developing Competence. London: Kogan Page.

30. Parsloe, E. (1999). The Manager As a Coach and Mentor. London: The Guernsey Press.

31. Pertin, R. D. (2011). Mentoring: A Business Strategy that Works. eBook: Rene D. Pertin Management Mentors Inc.

32. Podsen, I. J. \& Denmark, V. M. (2000). Coaching and mentoring first year and student teachers. Larchmont, NY: Eye on Education.

33. Robinson, T. (2001). Mentoring Speeds The Learning Curve. Information Week, 832(9), 77-78

34. Saul. J. (2004). Creating Mentoring Relationship. Available at: http://gbgm-umc.org/Response/ articles/mentor.html (Accessed, 2019).

35. Shula, D., and Blanchard, K. (2002). The Little Book of Coaching. Motivating People to be Winners. HarperCollins Publishers.

36. Straus, S. E., Chatur, F., and Taylor, M. (2009). Issues in the mentor-mentee relationship in academic medicine: A qualitative study. Academic medicine, 84(1), 135-139.

37. Vogt, F., and Rogalla, M. (2009). Developing adaptive teaching competency through coaching. Teaching and Teacher Education, 25(8), 1051-1060.

38. Waugh, T. A. (1997). Coaching for success. The CPA Journal, 67(8), 75.

39. Weaver, M. A., and Chelladurai, P. (1999). A mentoring model for management in sport and physical education. Quest, 51(1), 24-38.

40. Wilson, J. A., and Elman, N. S. (1990). Organizational benefits of mentoring. Academy of Management Perspectives, 4(4), 88-94.

41. Xavier, S. (2004). The Coaching FAQ. Available at: http://www.cornerstone-edg.com/coaching_ faq.html\#ec (Accessed 2019). 